\title{
The Effectiveness of Using Kagan Strategies in Eight Grad Students Achievement and the Development of their attitudes towards Science Education
}

\author{
Dr. Fawaz Hassan Ibrahim Shehada \\ Associate Professor, Department of Management and Curriculum \\ Faculty of Educational Science \\ Middle East University, Amman, Jordan.
}

\begin{abstract}
The purpose of this study is to gain insight into the effectiveness of using of Kagan's strategies for eighth grade students achievement and to develop their attitudes toward science. To achieve this goal, the study utilized an achievement test to measure the students' attitudes toward science, a measure of attitudes towards science which is prepared by the researcher and the teacher's guide uses Kagan strategies. The validity of the instrument of the study has confirmed. The number of study size (56) students and were divided into two groups: experimental group with (28) students and controlled group with (28) students also, the experimental group will be taught through the training program and the controlled group will be taught in the traditional way. The study resulted on an existence of a statistical significance in the applications of the pre- and post-tests of the achievement, there were also statistical differences in the two applications of the pre and posttests of the science trends measure, and for the favor of the post application. The study recommends that Training teachers on modern trends in teaching including strategies and design classrooms that allow teaching according to the modern teaching methods that require those designs.
\end{abstract}

\section{INTRODUCTION}

Workers in the field of curriculum and teaching methods aimed to reach strategies and methods to help teachers to manage the educational situation successfully. The success of the teacher is no longer limited to the achievement degree of his students for the purposes of the subject he teaches, but his success extended to the quality of what he instills in his students, the development of their behaviors, attitudes and values, so curriculum and teaching scientists are exploring, studying and finding results. The latest strategies that scientists are exploring are collaborative and active learning.

Kogak (2001) indicated that interests in studying cooperation and interaction in the educational situation began in the late 1960s, and the emergence of interaction studies analysis in educational situations, encouraging discussion among students, interest in teacher questions during explanation, types and levels of thinking developed by different types of questions and teachers and students behavior. Studies continued in its development, the most notably among them is a study by a research team, headed by Spencer Kagan at the University of California, United State of America, Kagan used 50 students as a teacher in the field training period. They were studying for about 2,000 students from primary school. Some students used teachers to teach traditional methods, while others used strategies based on student collaboration in learning. The results of the study showed that students who learned through the cooperative education gained important social behaviors, as well as their improvement in their academic achievement, as a result of that many studies called for the need to train teachers on cooperative learning strategies, notably Kagan strategies. 


\section{The Problem}

Based on the personal experiences of some teachers in science teaching, as well as the experience of the researcher in this field, it was noted that school students suffer from low achievement in science. The fact that the majority of traditional teaching methods transformed science into information necessitated the search for new methods that could contribute to help students develop their skills, achievements, and attitudes toward science. Kagan's strategies, which replace traditional teacher-centered learning methods in a student-centered way, as it gives positive results in academic achievement, the development of thinking skills, social skills, love of school and learning. Kagan's strategies are based on the principle of collaborative learning. It is a prerequisite for studies that have proved beneficial to learners. Kagan's strategies are linked to fun and entertainment, Therefore, educational strategies are described as easy to use, easy to use, easy to learn and use; and the best way to upgrade the learning process (Amin, 2008).

A review of the educational literature related to the subject of the study noted the scarcity of studies, according to the researcher, at the local level, which tried to train students on a set of Kagan strategies with a view to developing the achievement of the eighth students and developing their attitudes toward science. It is hoped that this study will provide an organized way to understand science in the hope of increasing their academic achievement and developing their attitudes towards science. This study is designed to meet the urgent needs of students and their teachers by providing a range of Kagan strategies to help achieve this goal.

\section{Research Questions}

The study aims at answering the following research questions:

1) Are there statistically significant differences at the level of significance $(0.05 \geq \alpha)$ between the average scores of the experimental group and the average scores of the control group students for the post-application of the achievement test?

2) Is there a statistical significance for the mean $((0.05 \geq \alpha)$ between the mean of the students of the experimental group and the average of the students of the control group in the remote application of the trend scale towards science?

\section{The Purpose of the Study}

The aim of this study was to determine the effectiveness of a set of Kagan strategies in the eighth grade student's achievement and to develop their attitudes toward science.

\section{The Importance of Studying}

The importance of the study lies in:

- The current study is expected to benefit the curriculum developers and practitioners to adopt the Kagan strategies in detail, as described in the study, as an important part of the content of the Science Teacher's Guide and its inclusion in the various stages of the study.

- The results of the present study may be useful to authors of science books and its methods of teaching by providing guidance and proposals to formulate content according to Kagan strategies.

- $\quad$ The current study may enrich research and studies in modern teaching strategies such as Kagan's strategies.

- The results of the present study may help supervisors and teachers develop teaching methods and employ them in teaching and learning processes. 


\section{The Limits of the Study}

There are a set of determinants that need to be taken into consideration when circulating the results of this study:

The current study was limited to using the following strategies: "KWL Strategy", "Questions Cube Strategy" and " The Other Half Strategy " in the achievement of students in the Eighth Grade students in Jordan and their development towards science in a sample of the eighth grade students in Irbid Governorate Schools for the academic year 2017/2018 by using the special tools for the study. Therefore, the validity of this study and its dissemination is linked to the previous variables with the used tools and the experimental sample members.

\section{Study Terms and Definitions \\ Kagan Strategies:}

In this research, the researcher defines Kagan's strategies as procedural: sequential procedural steps consist of a set of strategies, methods, and activities designed, planned, organized and intended (prepared by the researcher).

\section{Academic Achievement:}

The degree obtained by the student in the science achievement test on all multiple choices (20) paragraphs.

\section{Eighth Grade Students who sit in school in their eighth year.}

Trends towards science

A set of beliefs acquired by the individual through his contact with the environment around him, He may favor something, accept it, object or reject it (Abu Hammam, 2013). The researcher defined them as the result of students' responses to science, and were measured in the current study to the degree that the student obtained in identifying the trends towards the sciences which were specially prepared to measure their attitudes towards science in all the 20 paragraphs.

\section{The Study Community}

Includes all students at the $8^{\text {th }}$ grade in Irbid Governorate

\section{The study sample:}

It consists of two parts, one of which is the experimental group, which teaches a unit of the curriculum using the Kagan strategies, and the other is the control group, which is the same unit in the traditional way. Table (1) shows the distribution of the study sample.

Table 1: Distribution of the Study Sample

\begin{tabular}{|l|l|l|}
\hline The teaching strategy of the substance unit in the science book & Number & Percentage \\
\hline Kagan's strategy & 28 & $50 \%$ \\
\hline The traditional method & 28 & $50 \%$ \\
\hline Total & 56 & $100 \%$ \\
\hline
\end{tabular}

\section{Study Tools}

\section{Achievement Test}

To detect the effectiveness of Kagan's achievement strategies, the researcher prepared an achievement test. The final version of this test consists of 20 paragraphs of multiple choices with four alternatives. 


\section{Achievement Test Validity:}

The test was presented to (11) arbitrators to ascertain its validity. The arbitrators are a university professors in the field of science curricula and teaching methods and holders of master's and doctorate degrees, a number of educational supervisors in science and a number of science teachers who have experience in the educational material To express their views on the veracity of the test paragraphs in terms of: belonging to all paragraphs established, scientific and linguistic formulation, and the validity and suitability of alternatives, and any other suggestions for amendment.

\section{Achievement Test Stability:}

After verifying the logical veracity of the test content by arbitration, the test was confirmed, Where the researcher applied the test to a sample of students consists of (25) students. The test was calculated in a "Kronbach's Alpha" method with an alpha coefficient of (0.71), The test is re-applied to the same sample with a two-week interval, and the stability coefficient is applied (0.74), indicating the validity of the test for application and use.

\section{Identifying Trends towards Science}

In order to determine the effectiveness of Kagan's strategies in developing students 'attitudes towards science, a questionnaire was prepared to estimate students' attitudes towards science. This questionnaire consisted of (20) paragraphs with a triple scale. Either are "OK" or "not sure" or "Dissenting".

\section{Honesty Trends towards Science:}

The researcher presented the questionnaire to (11) arbitrators to ascertain their true honesty. They are university professors in the curricula of science and methods of teaching, measurement and evaluation of the holders of master's and doctorate degrees, and a number of educational supervisors in the field of science and a number of science teachers who have experience in the educational material, To express their views on the appropriateness of the paragraphs with the dimensions of the scale and their linguistic suitability, and any other proposals for amendment.

\section{Stability of the Study Determination of Trends towards Science}

The researcher applied the scale in its primary image to a sample of 25 students, The stability of the scale was calculated using the "Kronbach Alpha" method where the alpha coefficient (0.66) As a result, the standard test method of re-testing the re-application of the sample to the sample of the test itself with a difference of two weeks, The application stability factor (0.68) is calculated, indicating the correctness of the application and use parameters.

\section{STUDY METHODS AND EXPERIMENTAL DESIGN:}

The researcher used the following two methods:

1. Analytical Descriptive Approach: In presenting Kagan strategies, how to construct them, teachers' and students' roles and when to use them, and measure the students' mean in the control group in the in the post test application of the trend scale towards science.

2. Semi-empirical approaches based on two sets of tests, both experimental and quasi-test, as two groups, experimental and control, chosen by the research community.

As the achievement of students was measured among students in the eighth grade students in the experimental group (before and after applying Kagan strategies). 


\section{Statistical Processing:}

To answer the current study questions, to determine the effect of treatment on the dependent variables, the independent sample t-test was performed for each of the study questions.

\section{STUDY PROCEDURES}

The current study was carried out according to the following steps:

1. Preparing the study tools by referring to the literature of the theoretical study and previous studies that are consistent with the objectives of the current study, and then presented it to a group of arbitrators, who are specialized in curricula and educational psychology, to verify the accuracy of the paragraphs and their relevance, they have proposed some amendments and has been applied for the eighth grade students.

2. Distribution of the study tools on a sample of 25 students in order to verify the validity of the study tools and its stability, and to ascertain whether the paragraphs of the tools are clear and understandable to the sample of the study.

3. The data was entered into a computer and the statistical analysis program was used for statistical analysis. This was done after the study tools were applied to the study sample. All data and information presented by the students in the study tools were analyzed and interpreted.

\section{THEORETICAL LITERATURE AND PREVIOUS STUDIES}

Kagan strategies are one of the most successful programs in collaborative learning because they are related to other aspects including: individual differences, social skills, building team spirit, building a classroom environment, and other features that make the most successful schools are those who employ such strategies. they are multiple strategies implemented by the teacher with his students in order to stimulate students' thinking, develop their thinking skills in a practical way to employ them in their daily lives and experiences, raise their thinking level, and accordingly raise their achievement level, self-esteem and confidence building. Solving the problems, contributing to the building of his community, and developing the work of the team spirit in the student, and achieve the learner's activity and its positive in the discovery of information, which helps to keep learning, in addition to helping the student to develop the skills of oral communication, Social and accept the opinion of the other, And helps to promote positive relationships within the classroom (Amin, 2008). Shehab (2008) notes that Kagan has more than 150 strategies with different functions, some designed to achieve collective consensus and the other to generate thinking and other skills to generate communication skills.

After the researcher has studied Kagan strategies and the features and roles of both teacher and student, they chose three Kagan strategies to teach the experimental group. These strategies are:

\section{KWL Strategy:}

The KWL strategy is one of the active learning strategies developed in 1980 by Graham W. Detrick, where he introduced a set of building-based teaching strategies that are rooted in the Piaget psychologist, In 1986, Ogle Donna developed and finalized the strategy and became known as the K.W.L strategy where the first letter (K) refers to what I know. What I Know? The second letter (W) indicates what I know? And the third letters (L) to what have you learned? What I Learned? (Abu Gadwa \& Nofal, 2007).

Attiya and Saleh (2008) define KWL as a constructive learning strategy, which records all the students' prior knowledge of a subject, then decides and records what they need in light of the teacher's information, then records what they have already learned, and this can be done 
individually or in groups that are organized by the teacher as the situation requires. Kopp (2010,) defined it as a strategy used by the teacher to stimulate student thinking on a subject of a lesson before the new learning. Al-Barakati (2008) defined it as a planned action by the teacher to improve reading comprehension; it aims to guide readers, through steps followed by learners when reading an explanatory material. They are widely used in reading but can be adapted for use in science research.

This strategy consists of a set of planned steps planned by the teacher that contribute to organize and summarize thinking. It consists of three steps that require answering three questions about the learner's knowledge of a subject, what he will learn? and what to learn about the topic under study which leads to organizing thoughts and to assess Learner's efforts in studying and researching. It consists of three pillars:

- $1^{\text {st }}$ Column: What do you know? It means all the information and knowledge that the student has already learned about this topic and writes an answer to what you know in the first column.

- $2^{\text {nd }}$ column: What do you want to know (learn)? It means all the questions by the students to understand new things in the subject and the teacher practices a number of activities and learning methods such as surveying, dialogue, discussion and brainstorming and other methods that he sees useful to the student to give him an idea of what he wants to learn. The answer is written in the second column.

- $\quad 3^{\text {rd }}$ column: What did you know (learned)? It is the assessment questions that the teacher raises about the subject which evaluate the way he taught his students through their answers. The answer is written in the third column.

KWL's strategy is to give students the opportunity to remember and present their knowledge about a subject, as well as give them an opportunity to think about what they hope to learn after the classroom situation, and to offer them feedback on what they have learned at the end of the lesson. The teacher can pave the way for the lesson or link the new learning to the previous one through this strategy, and to ask students to fill $(\mathrm{K})$ and $(\mathrm{W})$ and leave the third column (L) to be filled at the end of the school class (Fatehallah,2014). This strategy emphasizes the activity of the learner in the formation of the meaning of the information. The student organizes the information and distinguishes between the different types of important information in the lesson (facts, context, causes, problems, solutions, concepts, principles) The establishment of these distinctions is the basis for effective learning, which involves abstraction of information, represented in the long-term memory in a way that is accessible later. This strategy is very effective in helping students to construct and configure meaning (Awad \& Said, 2002).

\section{Cube Strategy Questions}

One of Kagan's cooperative learning strategies, it is an enjoyable strategy that gives an fun atmosphere in the class, the idea it present is a motivational situation of thinking (text, story or video tape), then ask questions using a cube of questions, these questions are designed to be of different levels and are classified according to Bloom's classification of cognitive objectives which are knowledge, understanding, application, analysis, synthesis, and evaluation. In each side of the cube, the question is written, then the cube is thrown between the students groups, so that the question which written on the upper face of the cube belongs to that group and so on; the roles will be distributed to the team members (the one who through the cube, the one who ask and the one who answer). The roles are redistributed at the other time (Shehab, 2008). 
The cube method stimulates students to learn about the subject from six dimensions: description, comparison, correlation, analysis, conversion, translation and proof as the teacher builds the cube after the completion of the explanation, and the students can fill the gaps inside the cube after the teacher completion of the explanation, and here the teacher can divide the class into six groups each group takes one face of the cube, or he divides the class into six groups with six students each, so that each student takes one of the faces of the cube as a final assessment at the end of the class students fill the gaps in the cube (www.kaganonline).

\section{Looking for the other Half Strategy}

It is the strategy that the teacher prepares a set of colored cards before the lesson according to the number of students and writes questions on half of the cards and answers on the other half (each card one question or one answer). The teacher also explains the lesson completely, and distributes cards randomly to students so that each student gets only one card with a question or an answer written on it. Each student is then asked to look for the other half (as a type of review) and eventually each student must read the question and answer it. The number of cards can also be twice bigger than the number of students in the class so that each student will receive two cards with a question and another answer to another question, then each student should search for the answer to the question he has and gives his colleague the answer to his question (As a kind of intellectual challenge, not all cards may contain one answer). The cards contain selected phrases from the lesson. Each student must read his or her card, judge the correctness or mistake of the written word, discuss it with his colleagues, or try to get rid of the cards he fails to judge and give it to his colleague.

After or before completing the lesson, the teacher can distribute the cards that contain the questions only to the students. Each student should search for answers to these questions without going back to the book. The student who can collect the most questions with their answers is considered a hero or knight of the class and has a suitable prize. The teacher can ask a student a question and select one and ask him to answer within one minute. If he cannot answer within the prescribed period of time, the student will remain standing and turn the question to another student or ask a new question to another student.

This method is suitable for training students to speak and think quickly at a specific time.

These three strategies are attributed to Spencer Kagan, the teacher in the United States of America, who began to apply his theories of cooperative learning and practice plans and structures in his school in 1980 in order to develop education and stay away from the old methods, teachers response was amazing and the aid went on until they opened up whole provinces to apply his theories. These strategies replace the strong reliance on traditional teacher-centered learning methods in the world's largest group of student-centered educational policies. This shows that these strategies give positive results in academic achievement, the development of thinking skills, social skills, in addition to emotional intelligence, loving school, class, self, others and learning. The Kagan strategies are based on the principle of collaborative learning, which is a prerequisite for what the studies have proved to be of benefit to learners. Kagan's strategies are related to fun and entertainment, so it is characterized by the strategies of educational games for its ease and ease of application, easy to use and easy to learn and use; Kagan's participants spontaneously logo Kagan: "Learn it today; use it tomorrow; apply it for life" (Amin, 2008).

\section{PREVIOUS STUDIES}

Al-Gharabli (2011) conducted a study aimed at identifying the effectiveness of Kagan structures in increasing the achievement in the music education of the fifth grade students. The 
study used the experimental method. The study sample consisted of (40) female students. They were divided into two groups: experimental groups (20 students) and controlled group (20 students). The results indicated the effectiveness of the program based on the strategy of Kagan structures in raising the level of achievement in the subject of music education, and recommended in the study in light of the results of the need to train teachers and the application of Kagan structures in their subjects to increase students motivation to cooperate among themselves through collaborative learning strategies to instill cooperation value with themselves.

Al-Azzawi and Nasser (2010) conducted a study aimed at identifying the impact of teaching by using one of the Kagan strategies which is KWL on the students achievement in the third stage in the department of Science curriculum and methods of teaching at the Faculty of Education / University of Mustansiriya. The measurement tool was designed for the experimental group using the KWL strategy and the control group in the traditional way. The results of the statistical analysis showed a difference between the mean of the two groups in favor of the experimental group at the higher thinking levels and at the minimum thinking levels at the $5 \%$ level.

Attia and Saleh (2008) conducted a study aimed at identifying the effectiveness of two Kagan strategies (KWLA) and think -double -participate in teaching science to develop communication and mathematical creativity among primary students. Their results showed that the experimental group which used Kagan strategies was superior to the control group which used the traditional way.

Hafez (2008) conducted a study aimed at identifying the effectiveness of using some of Kagan's strategies, the collective cooperative education strategy and the KWL strategy, in developing reading comprehension skills among sixth graders in Saudi Arabia. The results of the study showed that the experimental group that used Kagan strategies is superior in developing reading comprehension skills than the control group studied in the traditional way.

Comment on previous studies:

It is clear through the study of educational literature and previous studies that there are many studies focused on the Kagan subject in achievement, but studies that tried to link these combined variables were rare at the local and regional levels, and this increases the importance of this study and provides a strong justification for its application.

\section{STUDY RESULTS AND DISCUSSION}

\section{First: The Results of the First Question Related to the Achievement Test:}

The question is, "Are there statistically significant differences at the level of significance $0.05 \geq$ $\alpha$ ) between the mean scores of the experimental group and the average scores of the control group students in the post-test of achievement?"

To answer this question, the researcher used an independent T sample test (T). Table 2 shows the results of the analysis: 
Table 2

Test results $(t)$ to test the difference between the two groups in the post-achievement test.

\begin{tabular}{|c|c|c|c|c|c|c|l|}
\hline The tool & The group & The sample & $\begin{array}{l}\text { The } \\
\text { average }\end{array}$ & $\begin{array}{l}\text { Slandered } \\
\text { defusing }\end{array}$ & $\begin{array}{l}\text { T } \\
\text { value }\end{array}$ & $\begin{array}{l}\text { Degree of } \\
\text { freedom }\end{array}$ & $\begin{array}{l}\text { probability } \\
\text { value }\end{array}$ \\
\hline $\begin{array}{c}\text { Eligibility } \\
\text { Test }\end{array}$ & Experimental & 28 & 13.86 & 3.26 & 4.479 & 54 & $00.0^{* *}$ \\
\hline & Control & 28 & 10.03 & 3.12 & & \\
\hline
\end{tabular}

** Mean: Statistical significance at the level of statistical significance $(\alpha=0.05)$

Table (2) shows that there is a statistically significant difference in the mean $(0.05 \geq \alpha)$ between the mean scores of the experimental group and the average score of the control group's applications in the post application of the test. For the benefit of the experimental group, this was studied in accordance with Kagan strategies. The average score of the students in the experimental group was 13.86 and the standard deviation was 3.26 , while the average of the students in the control group was 10.03 and the standard deviation was 3.12 .

The researcher attributed the effectiveness of Kagan's strategies to the development of student achievement in science, saying that these strategies broke the routine and made students live in an atmosphere of interaction and vitality which enabled them to interact and participate in discussions while learning, and enabled them to acquire, discover and apply information in new situations. In addition to making them more active in the performance of the tasks assigned to them, which stimulated their motivation to fulfill the tasks required of them. They also provided them with positions that motivated them and attracted their attention. It also challenged them because they received training and activities that enhanced their ability to learn, which played a major role in increasing their achievement.

This result can be attributed to the fact that Kagan's strategies as perceived by many educators are unconventional strategies centered around students, which have led to positive results in their academic achievement, the development of their social skills, increasing their desire for learning love of self and others; because they use collaborative learning and educational activities and learning activities, cooperation with the students of one group, which made them more positive and effective in the activities of educational material, and this contributed to the need to learn within the classroom to help them improve their level of achievement. This finding can be explained by the fact that Kagan's strategies have promoted the idea of education that makes students the focus of the learning process rather than the teacher, by reviving their previous knowledge and arousing their curiosity. They are a mixture of different organizations that fit specific cognitive and social goals. It helps students to acquire collaborative learning skills in practical and simple ways that give the classroom a sense of fun, fun, self-confidence, and love of cooperation among students by organizing the classroom environment. The result of this study was agreed with the results of the study of: Gharabli (2011), Al- Azzawi and Nasser (2010), Attia and Saleh (2008) Hafiz (2008), all of which indicated the superiority of the experimental group studied according to Kagan strategies.

\section{Second: The Results of the Second Question Concerning the Measure of Trends towards Science}

The question is: "Are there statistically significant differences at the level of $(0.05 \geq \alpha)$ between the mean of the experimental group's students and the average of the control group's students in the post- application of the trend scale towards science?" 
To answer this question, use the independent T sample test (T). Table (3) shows the results of the analysis:

Table 3

Test results ( $t$ ) to test the difference between the two groups in the post-directions scale.

\begin{tabular}{|l|l|l|l|l|l|l|l|}
\hline The tool & The group & $\begin{array}{l}\text { The } \\
\text { sample }\end{array}$ & $\begin{array}{l}\text { The } \\
\text { average }\end{array}$ & $\begin{array}{l}\text { Slandered } \\
\text { defusing }\end{array}$ & $\begin{array}{l}\text { T } \\
\text { value }\end{array}$ & $\begin{array}{l}\text { Degree } \\
\text { of freedom }\end{array}$ & $\begin{array}{l}\text { The value } \\
\text { of probability }\end{array}$ \\
\hline $\begin{array}{l}\text { Eligibility } \\
\text { Test }\end{array}$ & Experimental & 28 & 2.42 & 0.96 & 5.09 & 54 & $00.0^{* *}$ \\
\hline & Control & 28 & 2.20 & \multirow{2}{*}{0.21} & & & \\
\hline
\end{tabular}

** Mean: Statistical significance at the level of statistical significance $(\alpha=0.05)$

Table (3) shows that there is a statistically significant difference in the mean $(0.05 \geq \alpha)$ between the average of the students of the experimental group and the average of the students of the control group in the post application of the trend scale towards science due to the experimental group, which was studied according to your strategies. The average of the experimental group's scores in the GPA was 2.42 and the standard deviation was 0.96, while the average of the students in the control group was 2.20 and the standard deviation was 0.21 . The researcher attribute this finding to the fact that Kagan's strategies have been able to influence students' attitudes towards science, making science more fun, exciting and fun, and make them enjoy studying science and how to teach it, In addition to their presence in groups showed the clear role of each student, which increased their motivation to achieve and raise the level of confidence and love of science, and this has a positive impact in their attitudes towards science.

This finding can be explained by the fact that the use of Kagan strategies has been instrumental in helping students acquire information and their ability to apply it in practical and simple ways. He is therefore expected to develop positive attitudes towards science. In addition, the students' practice of collaborative learning adopted by Kagan Strategies, which has an active learning environment during learning, facilitates cooperation, making them more positive and effective, which has played a prominent role in the development of positive attitudes towards science. In addition, the Kagan strategies used in this study by students for the first time may have made the teaching of science in this way tempting them, and perhaps even developing their positive attitudes towards science. The results therefore indicate that Kagan's strategies are superior to the traditional way of developing students' positive attitudes toward science.

\section{RECOMMENDATIONS}

After completing the presentation and interpretation of the results, the researcher recommends:

1. Training teachers on modern trends in teaching, including strategies.

2. Design classrooms that allow teaching according to the modern teaching methods that require these designs.

\section{References}

Atteya, I. \& Saleh, M. (2008). Strategic Effect (k. w. l.) \& (Think, Combine, Share), cooperate the Mathematics is based on the development of the communication and mathematical creativity at a Primary stage School. Journal of Faculty of Education, 18 (76), 50-85. 
Amin, $O$ (2008). The effectiveness of the role-sharing strategy in the development of critical thinking and Achievement and the retention of the history material of secondary students in Madinah, Master Thesis Unpublished. University of Taiba, Faculty of Education and Human Sciences, Department of Curriculum and Teaching Methods social science, Madina El Monawarah.

Shehab, B. (2008). Forums Sharjah Educational Zone, Retrieved from: http://www.sez.ae/vb/showthread.php?t=74682.

Abu Hamam, A. (2013). The effectiveness of a computerized training program to teach computer Applications in developing some computer skills for Al-Azhar University students - Gaza, and their Attitudes toward them. Unpublished MA. Al-Azhar University - Gaza, Palestine.

Awad, A \& Habib, S. (2002). The impact of using meta-knowledge strategies in teaching Literary texts in the secondary stage of Cairo Governorate schools. Six Scientific Conference, Ismailia, 28-31, July.

Hafez, W.(2008). Effectiveness of using collective learning strategy and KWI strategy in Developing Reading comprehension skills among sixth grade students in Saudi Arabia, Journal of Reading and Knowledge, Egyptian Society for Reading and Knowledge. No. 74, 228-154.

Abu, S \& Nofal, M, (2007). Teaching thinking, theory and practice: Amman: Dar almasira for publishing Distribution and printing.

Kogak, K. (2001). Recent trends in curriculum and teaching applications in Family Education, Cairo: The World of Books Printer.

Ibrahim, M. (2005). Thinking from an educational perspective - definition - nature - skills -Cairo: The World of Books.

Alhilah, M (2008). Educational games and their production techniques (Edishion3). Amman: Dar almasira For publishing Distribution and printing.

Al-Gharrabli, M (2011). Effectiveness of the use of Kagan structures as a method of collaborative learning In an increase Achievement in music education for fifth graders in basic education In the United Arab Emirates. Unpublished doctoral thesis.

Fathallah, M (2015). Analysis of the content of science books (concepts and applications). Riyadh: Dar alnashr alduwaliu.

Al-Azawi, N (2010). The impact of teaching using the KWL strategy in scholastic achievement In Curriculum and Teaching Methods for Third Stage Students in the Department of Science of the Faculty of Education /Mustansiriya University.

AL barakati, N. (2008). The impact of teaching using the strategy of multiple intelligences and six hats And (kwl) in the achievement, communication and social cohesion of third-grade students in the City Of Mecca, unpublished doctoral thesis, Faculty of Education, Umm Al-Qura University, Makkah Al Mukarramah.

Nabhan. Y (2012). Modern methods of teaching and learning, (edition 2). Amman: Dar Al Yazuri Scientific Publishing and Distribution.

Kagan, S.(2009). Cooperative Learning. San Clemente, CA: Kagan Publishing, Retrieved from http://www.kaganonline.com/

Kopp, K. (2010). Every Content Area- Writing to Learn Strategies for Grade 3-5.first edition Gainesville, Maupin House.

Rashid, I. (2015). Academy of Ibrahim Rashid. Retrieved from: http://www.ibrahimrashidacademy.com/ 